\title{
The Application of Seamless Nursing to Patients with Nephrotic Syndrome
}

\author{
Yingxue Zhong ${ }^{1}$, Qingqing Zhai ${ }^{2, *}$ \\ ${ }^{1}$ Department of Renal Rehabilitation, the First Affiliated Hospital, Jinan University, Guangzhou, China \\ ${ }^{2}$ External Renal Thoracic Surgery Department, the First Affiliated Hospital, Jinan University, Guangzhou, China \\ Email address: \\ Yingxuezhong456@163.com (Yingxue Zhong), qingqingzhai456@163.com (Qingqing Zhai) \\ *Corresponding author
}

To cite this article:

Yingxue Zhong, Qingqing Zhai. The Application of Seamless Nursing to Patients with Nephrotic Syndrome. American Journal of Nursing Science. Vol. 9, No. 4, 2020, pp. 193-195. doi: 10.11648/j.ajns.20200904.13

Received: April 29, 2020; Accepted: May 18, 2020; Published: June 3, 2020

\begin{abstract}
Objective: To assess the application of seamless nursing to patients with nephrotic syndrome. Methods: 88 nephrotic syndrome patients agree to join our study, they were diagnosed as nephrotic syndrome in the hospital from May 2018 to October 2019. The participants were randomly assigned the participants to two groups, that include control group $(\mathrm{n}=44)$ and intervention group $(n=44)$. We provide conventional nursing service to the control group participants in the treatment process. Also, intervention group participants receive seamless nursing services. Our researchers collected anxiety information and depression information by questionnaires which include Self-Rating Anxiety Scale (SAS) and Self-rating depression scale (SDS). In addition, we collect the information was associated with participants characteristics from hospital database and participant satisfaction of satisfaction questionnaire. Result: In depression- and anxiety- research result, the two groups have similar assessment result in SAS and SDS of before the nursing, they are not statistical significance. However, the result of after the nursing is different in SDS and SAS. The intervention group participants have better performance in SAS and SDS result (34.21 \pm 1.26 vs $44.21 \pm 3.83,32.37 \pm 2.81$ vs $46.51 \pm 5.7)$. In patient satisfaction research, all participants have good satisfaction assessment for nursing service $(95.5 \%$ \& $77.3 \%)$. But intervention group has obviously improvement in our research result. In intervention group assessment, most assessment are very well $(\mathrm{n}=24)$. Conclusion: The seamless nursing has strongly improvement to depression and anxiety of patient, and patient satisfaction.
\end{abstract}

Keywords: Nephrotic Syndrome, Seamless Nursing, Nursing

\section{Introduction}

One of the best-known manifestations of kidney disease is nephrotic syndrome (NS), its primarily feature contains heavy albuminuria with hypoalbuminaemia, hyperlipidaemia and peripheral oedema [1]. In addition, idiopathic nephrotic syndrome is a glomerular disease characterized by proteinuria, which leads to hypoalbuminemia and peripheral edema [2]. A good number of NS patients act in response to steroid therapy, but $15-20 \%$ of them fail to respond to steroid treatment [3]. The dialysis or transplantation may are this outcome in end-stage kidney disease. Base on the report, NS can cause disordered lipid and lipoprotein metabolism. Its disease characteristics is abnormal levels of plasma triglycerides, cholesterol, and lipoproteins, including very low-density, low-density, and high-density lipo-proteins. They are risk factors for cardiovascular and renal diseases [4-6]. Thus, NS is a severe clinical presentation that affects millions of patients worldwide [7]. If not treated timely and appropriately, it can cause serious consequences. The patients may develop into the end-stage renal disease, diminishing seriously their quality of life [8]. Additionally, NS had some treatment of problem, such as high recurrence rate, low curative rate, protracted illness and poor prognosis [9].

Nurses play a key role in healthcare delivery, they had pivotal role in treatment process, that include the provision and coordination of care, prevention of adverse events, and optimization of health service productivity and patient outcomes [10]. In healthcare quality, nurses had quality- and safety- responsibilities, it not only need to the provision of safe care that is aligned with best evidence and clinical standards but also need to participation in broader 
organizational and system quality and safety structures [11]. Furthermore, nurses are expected to encourage, participate in, and apply research evidence to improve the safety and quality of care and to demonstrate clinical leadership [12]. This study's aim is discussing application of seamless nursing to patients with nephrotic syndrome.

\section{Methods}

\subsection{Participants Enrollment and Survey Methods}

88 nephrotic syndrome patients agree to join our study, they were diagnosed as nephrotic syndrome in the hospital from May 2018 to October 2019. The participants were randomly assigned the participants to two groups, that include control group $(n=44)$ and intervention group $(n=44)$. We provide conventional nursing service to the control group participants in the treatment process. Also, intervention group participants receive seamless nursing services. Our researchers collected anxiety information and depression information by questionnaires which include Self-Rating Anxiety Scale (SAS) and Self-rating depression scale (SDS) [13-15]. Additionally, we collect the information was associated with participants characteristics from hospital database and participant satisfaction of satisfaction questionnaire.

In seamless nursing service process, firstly, we receive the medicine record of the patients so that we can clear know the nephrotic syndrome status of patient, it help doctor save the time to know patient's condition and connect patients to doctor. Thus, the patient can receive suitable care at once as we had been known the information which from other medical organization. Secondly, the patient receive quick procedure process and check process as the patient information was shared to all related department in the hospital. thirdly, our research follows up on the patient's condition after discharge.

Their inclusion criteria were: (1) the patients were diagnosed as nephrotic syndrome; (2) Patients volunteered to participate in follow-up; Their withdraw criteria were: (1) The participants had severe complications; (2) The patient also had other kidney disease.

\subsection{Statistical Analysis}

Our data analyzer performed the statistical analysis by SPSS 22.0. The $\mathrm{P}$ value, t-test and chi-square test were associated with collection result were analyzed. Besides, the mean standard deviation for statistical description.

\section{Result}

In Table 1, the participant characteristics information is shown in our research result. The influence factors are excluded, that contains patient age factor and patient gender factor. They are not statistical significance $(\mathrm{p}=0.715 \& \mathrm{p}=0.822)$.

Table 1. Participant Characteristics.

\begin{tabular}{lllll}
\hline Projects & Intervention group $(\mathbf{n}=\mathbf{4 4})$ & Control Group $(\mathbf{n}=\mathbf{4 4})$ & t & P value \\
\hline Gender (female), $\mathrm{n}(\%)$ & 18 & 19 & 1.832 \\
Age (years) & $44.68 \pm 12.98$ & $42.51 \pm 13.85$ & 0.715 \\
\hline
\end{tabular}

The Table 2 shows the depression assessment and anxiety assessment of participants, the data from SAS questionnaire and SDS questionnaire. The participants finish the SAS questionnaire and SDS questionnaire in follow-up. In this research result, the two groups have similar assessment result in SAS and SDS of before the nursing, they are not statistical significance. However, the result of after the nursing is different in SDS and SAS. The intervention group participants have better performance in SAS and SDS result $(34.21 \pm 1.26$ vs $44.21 \pm 3.83,32.37 \pm 2.81$ vs $46.51 \pm 5.7)$. This results are statistical significance $(\mathrm{p}<0.005)$.

Table 2. The outcome of SAS and SDS.

\begin{tabular}{|c|c|c|c|c|c|c|c|c|}
\hline \multirow{2}{*}{ Projects } & \multicolumn{2}{|l|}{ SAS } & \multirow{2}{*}{$\mathbf{T}$} & \multirow{2}{*}{ P value } & \multicolumn{2}{|l|}{ SDS } & \multirow{2}{*}{$\mathbf{T}$} & \multirow{2}{*}{ P value } \\
\hline & BN & $\mathbf{F N}$ & & & BN & FN & & \\
\hline Intervention Group $(\mathrm{n}=44)$ & $64.32 \pm 3.94$ & $34.21 \pm 1.26$ & 21.276 & $<0.005$ & $58.53 \pm 5.61$ & $32.37 \pm 2.81$ & 26.842 & $<0.005$ \\
\hline Control Group $(n=44)$ & $62.36 \pm 4.21$ & $44.21 \pm 3.83$ & 12.677 & $<0.005$ & $64.46 \pm 4.35$ & $46.51 \pm 5.7$ & 12.284 & $<0.005$ \\
\hline $\mathrm{T}$ & 1.017 & 22.27 & - & - & 0.904 & 14.320 & - & - \\
\hline $\mathrm{P}$ value & 0.858 & $<0.005$ & - & - & 0.161 & $<0.005$ & - & - \\
\hline
\end{tabular}

SAS = Self-Rating Anxiety Scale

SDS $=$ Self-rating depression scale

$\mathrm{BN}=$ before the nursing

$\mathrm{FN}=$ after the nursing

The patient satisfaction from simple questionnaire research. It indicates all participants have good satisfaction assessment for nursing service $(81.8 \%$ \& $65.9 \%)$. But intervention group has obviously improvement in our research result. In intervention group assessment, most assessment are very well $(\mathrm{n}=24)$. The satisfaction assessment of control group is evenly distributed in each grade of evaluation.
Table 3. The satisfaction of patients.

\begin{tabular}{lllll}
\hline Projects & Very Well & Good & Bad & Percent \\
\hline Intervention Group $(\mathrm{n}=44)$ & 24 & 18 & 2 & $95.5 \%$ \\
Control Group $(\mathrm{n}=44)$ & 16 & 18 & 10 & $77.3 \%$ \\
$\mathrm{X}^{2}$ & - & - & - & 3.415 \\
P value & - & - & - & 0.017 \\
\hline
\end{tabular}




\section{Discussion and Conclusion}

Nephrotic syndrome is a clinical condition characterized by massive proteinuria, hypoalbuminemia, and edema, with or without hyperlipidemia [16]. The nephrotic syndrome is caused by defects in the glomerular filtration barrier, but the etiology remains still is unclear in research. In addition, a charge- and size-specific barrier that is made up of specialized fenestrated endothelium, glomerular basement membrane, and specialized glomerular epithelial cells called podocyte [17]. Base on US's report, it is estimated the annual incidence of NS is 3 per 100,000 in adults [18]. But the situations of nephrotic syndrome were different as race and environment [19]. Based on its etiology, primary NS contains minimal change disease, membranous glomerulonephritis, mesangial proliferative glomerulonephritis, rapidly progressive glomerulonephritis and focal segmental glomerulosclerosis. Additionally, secondary NS include systemic lupus erythematosus, diabetic nephropathy, purpura nephritis, hepatitis B virus associated nephritis and renal amyloidosis [20].

As the above result, the seamless nursing has strongly improvement to depression and anxiety of patient, and patient satisfaction. In particular, the intervention group participants have better performance in SAS and SDS result, it indicates the seamless nursing can improve the mental health of patient. It is very important to treatment as more studies pay attention to patient's mental health before treatment and in treatment process. In satisfaction research, the intervention group participants provide better assessment, intervention group has more 'very well' assessment. In addition, the satisfaction rate of patient is higher in intervention group compare with those of control group.

\section{References}

[1] Jahan I, Hanif M, Ali MA, et al. Prediction of risk factors of frequent relapse idiopathic nephrotic syndrome. Mymensingh Med J. 2015; 24: 735-742.

[2] Andolino TP, Reid-Adam J: Nephrotic syndrome. Pediatr Rev. 2015; 36: 117.

[3] Nephrotic syndrome in children: prediction of histopathology from clinical and laboratory characteristics at time of diagnosis. A report of the International Study of Kidney Disease in Children. Kidney Int. 1978; 13: 159-165.

[4] Morris AW. Nephrotic syndrome: PCSK9: a target for hypercholesterolaemia in nephrotic syndrome. Nat Rev Nephrol. 2016; 12: 510.

[5] Agrawal S, Zaritsky JJ, Fornoni A, Smoyer WE. Dyslipidaemiain nephrotic syndrome: mechanisms and treatment. Nat Rev Nephrol. 2018; 14: 57-70.

[6] Mikolasevic I, Zutelija M, Mavrinac V, Orlic L. Dyslipidemia in patients with chronic kidney disease: etiology and management. Int J Nephrol Renovascular Dis. 2017; 10: 35-45.
[7] Eckardt KU, Coresh J, Devuyst O, Johnson RJ, Köttgen A, Levey AS, Levin A. Evolving importance of kidney disease: from subspecialty to global health burden. Lancet. 2013; 382: 158-169.

[8] Lu R, Zhou J, Liu B, Liang N, He Y, Bai L, Zhang P, Zhong Y, Zhou Y, Zhou J. Paeoniflorin ameliorates Adriamycin-induced nephrotic syndrome through the PPAR gamma/ANGPTL4 pathway in vivo and vitro. Biomed. Pharmacother. 2017; 96: 137-147.

[9] Cattran D, Brenchley P. Membranous nephropathy: thinking through the therapeutic options. Nephrol. Dial. Transplant. 2017; 32: i22-i29.

[10] Aiken LH, Sloane DM, Bruyneel L, et al. Nurse staffing and education and hospital mortality in nine European countries: A retrospective observational study. Lancet. 2015; 383 (9931): $1824-1830$

[11] Australian Commission on Safety and Quality in Healthcare. Clinical governance for nurses and midwives. Sydney: ACSQH. 2017.

[12] Melnyk B, Gallagher-Ford L, Long L, Fineout-Overholt E. The establishment of evidence-based practice competencies for practicing registered nurses and advanced practice nurses in real-world clinical settings: Proficiencies to improve healthcare quality, reliability, patient outcomes, and costs. Worldviews on Evidence-based Nursing. 2014; 11 (1): 5-15.

[13] White D, Leach C, Sims R, Atkinson M, Cottrell D. Validation of the Hospital Anxiety and Depression Scale for use with adolescents. Br J Psychiatry 1999; 175: 452-454.

[14] El-Rufaie O, Absood G. Validity study of the Hospital Anxiety and Depression Scale among a group of Saudi patients. Br J Psychiatry 1987; 151: 687-688.

[15] McPherson R., Frohlich J., Fodor G., Genest J., Canadian cardiovascular society position statement e recommendations for the diagnosis and treatment of dyslipidemia and prevention of cardiovascular disease, Can. J. Cardiol. 2006; (22): 913-927.

[16] Niaudet P. Steroid-resistant idiopathic nephrotic syndrome in children. In: Avner ED, Harmon WE, Niaudet P, eds. Pediatric Nephrology. Philadelphia, PA: Lippincott Williams \& Wilkins. 2016: 557-573.

[17] Chernin G, Heeringa SF, Gbadegesin RA, et al. Low prevalence of NPHS2 mutations in African American children with steroid resistant nephrotic syndrome. Pediatr Nephrol. 2018; 23 (9): 1455-1460.

[18] Eddy AA, Symons JM. Nephrotic syndrome in childhood. Lancet. 2015; 362 (9384): 629-639.

[19] Banh TH, Hussain-Shamsy N, Patel V, et al. Ethnic differences in incidence and outcomes of childhood nephrotic syndrome. Clin J Am Soc Nephrol. 2016; 11 (10): 1760-1768.

[20] Bonilla-Felix M, Parra C, Dajani T, et al. Changing patterns in the histopathology of idiopathic nephrotic syndrome in children. Kidney Int. 1999; 55 (5): 1885-1890. 